\title{
ICEBERG WATER: AN ASSESSMENT (Invited paper)
}

\author{
by \\ W. F. Weeks \\ (U.S. Army Cold Regions Research and Engineering Laboratory, Hanover, NH 03755, U.S.A.)
}

\begin{abstract}
This review of the idea of using icebergs as a source of fresh water starts with a historical survey covering the period up to April 1980 and stresses how the approach to the subject has changed with time. Both the progress that has been made and the problems that have either just surfaced or never been adequately addressed are discussed. It is concluded that successful tows to Australia, clearly the most easily-reached potential delivery site, are a possibility if icebergs can be demonstrated to retain their structural integrity during tows in high seas and if favorable schemes can be developed for docking and processing. Tows to sites in the northern hemisphere such as Saudi Arabia and California are significantly more difficult and will remain so until an effective and operationally-realistic method is developed for isolating the iceberg from the warm sea-water that will be encountered during part of the tow. Whatever the ultimate resolution of the iceberg-water proposal may prove to be, research stimulated by this idea has already resulted in a major improvement in our knowledge of the life and times of real icebergs in real oceans.
\end{abstract}

\section{INTRODUCTION}

During the next few minutes, I will attempt to give you my assessment of the current status of the subject of iceberg water. Is it or is it not a realistic possibility worthy of serious study? This question is to some extent answered by looking around this room. Assuming that we are not as a group bereft of our senses, I think it is safe to say that we all have considered iceberg water as sufficiently possible to have devoted some time to investigating the subject. However, before I start to inflict my personal opinions upon you, I feel that it is only fair that I attempt to state my particular sources of bias so that you can temper my comments with the appropriate amount of salt.

As many of you know, I was co-author with Bill Campbell of one of the papers (Weeks and Campbel1 1973) that led to the present meeting. As a matter of fact, a preliminary version of that paper was first presented at this very location eleven years ago during the vlaciological Society symposium on the hydrology of glaciers. In that presentation, we suggested that there was no apparent geophysical reason why large-scale iceberg towing to sites in the southern hemisphere could not be successful. Therefore, I would clearly be pleased if iceberg water were to become a reality as I could then lay claim to having been a very, very minor prophet. However, considering the fate that appears to befall many prophets, perhaps that is not too wise a goal. Because I was involved in getting iceberg water started, I have always been concerned that perhaps it would not work, since then I would feel that it was all my fault, and that I had wasted the time and efforts of a number of people. The end result is that I have a rather schizophrenic view of iceberg water. I want it to succeed in that I feel that such a scheme could have a great deal to offer to certain regions of the Earth with only minor negative side-effects. On the other hand, I am well aware of at least some of the problems and I am always afraid of finding in the scheme a critical flaw that should have been foreseen. Because of this nagging worry, I tend officially to be rather pessimistic and inclined to list difficulties which warn the neophyte iceberg tow-er that he is facing a series of problems that are far from routine. However, to identify problems clearly often speeds their solution. Finally, I am not currently involved in iceberg research, which presumably should provide some degree of impartiality to my comments.

\section{A HISTORY LESSON}

The origins of the idea of towing icebergs as a water source are obscure. Ice was definitely carried from Alaska to California in the 1850s for use as a refrigerant, and small icebergs were apparently transported from southern Chile to Valparaiso and Laguna San Rafael, and even as far north as Callao, Peru, also for use as a refrigerant. This operation has not been well-documented. It is a simple step to consider the transported ice as a source of water in addition to its cooling potential. The modern revival of the idea should be credited to J.D. Isaacs, whose work, although never published, focused on delivering Antarctic icebergs to water-hungry southern California and inspired several descriptions in the semipopular literature (Burt $1956[\mathrm{a}]$ and $[\mathrm{b}]$ ). The first published papers on the subject were the previously-mentioned work of Weeks and Campbell 
(1973) and a paper by Hult and Ostrander (1973). These two papers were similar in that both pairs of authors saw potential advantages in largescale operations, and they both assumed that the major uses of such water would be for either irrigation or industrial processes, but otherwise the two works were very different. Weeks and Campbell investigated the towing of individual, unprotected icebergs to the most easily reached destinations, such as Australia and other southern hemisphere sites, while Hult and Ostrander examined the transport of trains of insulated Antarctic icebergs to sites north of the equator, specifically to southern California. The obsession of Isaacs and of Hult and Ostrander with the more difficult problem of delivering ice north of the equator was undoubtedly the result of the fact that all three were residents of southern California and were aware of its water problems.

These papers caused a flurry of articles in the press (icebergs seem to fascinate journalists). Also, several small, informal, scientific meetings took place in which the general idea was discussed with the conclusion that it should not readily be dismissed as impossible even though a number of problems could be foreseen, some of which might be impossible to overcome. However, all in all, not much happened, except that a number of scientists and engineers, motivated by curiosity and skepticism, began to probe quietly into different aspects of the problem. I refer specifically to investigators such as Job, Fuhs, Josberger, and Swithinbank, and to my colleagues at CRREL, Mellor and Kovacs.

This is where things would probably have stayed, bubbling quietly on the back burner, but for the interest of one man, Prince Mohammed al Faisal al Saud. Prince Mohammed had become interested in iceberg water independently. At the time he was charged with developing the water supplies of Saudi Arabia, the largest country in the world without a single perennial stream, which therefore had real big-time water problems. Compared with Saudi Arabia, southern California looked like a tropical rain forest. Could iceberg water be the answer to the Saudi water problem specifically and the Middle Eastern water problem generally (Al Faisal, in press)? Prince Mohammed intended to find out and he set about this with considerable vigor. His interest in Saudi Arabia as a delivery site caused a major shift in emphasis with largely beneficial side-effects. Previous discussions of $i$ ceberg water had stressed its application to irrigation and agro-industrial complexes, schemes that could not afford high-priced water and demanded delivery of very large icebergs. Water delivered to Saudi Arabia, however, would be used for human consumption and high technology, and could command far greater prices. This more favorable cost structure made the economic delivery of much smaller icebergs a possibility, placing the whole operation nearer to the capabilities of present technology. Saudi Arabia presented numerous other difficulties: long tows through hot water (necessitating complete protection of the icebergs), shallow water, reversing currents, and severe tropical storms. Jeddah may not be the most difficult site on Earth to accept delivery of an iceberg, but it cannot be far from it.
The interest and support of the Prince also sparked two meetings prior to the meeting we are now attending. The first of these took place in Paris during the spring of 1977 and involved members of a French consulting group, CICERO, and a number of outside experts, several of whom are in this room. The exchange between the two groups was interesting and emphasized to me the importance of knowing real conditions on real icebergs adrift on the high seas. Without such knowledge, reasonablesounding engineering schemes can be developed that, in fact, have no chance for success. Although the scientists were able to burst a few of the engineers' bubbles, I should point out in all faimess that the scientists were asked many simple questions about real icebergs to which they could give no adequate answers. Clearly there was a need to get people together who were interested in iceberg water so that they could compare notes, establish what was and what was not known on the subject, and decide which topics were most in need of further examination.

The second event to be supported by Prince Mohammed occurred during the following fall at Iowa State University when a large meeting on iceberg utilization convened. Much of what I say during the remainder of this paper will be based on the papers of the Iowa meeting (Husseiny 1978), a fascinating assortment of studies varying from hard science and engineering to discussions of regional, political, and legal problems, to near-science fiction. Before we proceed to examine the state of the art as documented there, let us make a slight detour. Poeple who are fascinated with the possibility of iceberg water are commonly given to the delusion that only they are interested in icebergs. This is almost true where Antarctic icebergs are concerned. However, in the northern hemisphere this is far from the case. Firstly, the International Ice Patrol has been chasing icebergs ever since the Titanic slipped beneath the waves. Thus, there is a reasonable documentation of their comings and goings and ultimate disappearance in the waters of the North Atlantic. Admittedly, Antarctic icebergs are a slightly different class of beast, but nevertheless much can be learned from the behavior of their Arctic cousins. Secondly, oil companies, in carrying out offshore drilling in the waters off Labrador and Newfoundland, have had to contend with the very real possibility of icebergs colliding with their drill-ships and platforms. They have countered this hazard in a direct fashion by using tugs to deflect the icebergs. This interest in modifying the drift track of such icebergs, and also in forecasting the track so that one could ascertain when towing was required, led to the symposium on iceberg dynamics held in St John's, Newfoundland, in 1979 , the proceedings of which (Russell 1980) contain considerable information of direct interest to the present meeting.

\section{THE STATE OF THE ART}

I will now proceed in my usual manner by discussing things backwards, thereby in a general way placing the most important material last. This is undoubtedly a response to the fact that the first initial of my last name, being near the end of the alphabet, always 
resulted in my sitting at the back of the class Where are we on a number of different aspects of the iceberg-water problem? In my opinion roughly as follows:

Legal problems

As is we 11-known in the United States of America in 1980, one cannot have a large project without employing a similarly-sized group of lawyers. I see no reason to believe that this dictum will be avoided by an international iceberg-water project as, at first glance, it does appear to be traversing somewhat uncharted legal waters. However, it would appear that iceberg harvesting largely falls under the law of the sea, as the existing Antarctic Treaty specifically omits reference to mineral exploitation, therefore excluding icebergs from consideration. Besides, most pick-up sites are in international waters north of the Antarctic Treaty area. The discussions so far (Bishop 1978, Chamoux 1978, Burton 1978) suggest that most legal problems are tractable within established international procedures. However, it is undoubtedly wise to explore legal problems thoroughly as soon as operational tows appear to be a possibility. If a problem must be resolved before towing can start (for instance, if it is necessary to tow through the territorial waters of a coastal state), it would be far easier to reach agreement before rather than after the fact. In other areas where the law is "grey", it is probably wise not to ask too many questions and simply start operations.

Development of coupled projects

The immense masses of ice that are the initial products of any iceberg-towing scheme require equally large quantities of heat to convert them to water, the desired end-product. This giant heat sink has distinct advantages as it may be coupled with a variety of other industrial schemes that produce large quantities of waste heat to nullify both the hot and the cold aspects of the thermal pollution. A coupling of particular interest would use ice to increase the thermal gradient in an ocean thermal energy conversion (OTEC) scheme. Detailed analyses of this possibility are given by Heizer (1978) and by Roberts (1978). As Schwerdtfeger (1979) has pointed out, a $1 \mathrm{~km}^{3}$ iceberg has a mass of roughly $9 \times 10^{11} \mathrm{~kg}$ and represents $3 \times 10^{7} \mathrm{~J}$ of energy in a $0^{\circ} \mathrm{C}$ environment. If this can be converted to electric power with an efficiency of $3 \%$ we produce $2.4 \times 10^{9} \mathrm{kWh}$ which would have a value of $\$ 120$ million if priced at $5 \$ / \mathrm{kWh}$. This is a handsome profit, considering that we needed to melt the ice in the first place. Before we become too enthralled by these large figures, it is good to remember that these advantages are only possible if we can deliver the ice. The only help that they might provide in delivery is that one should be able to expend more funds on a delivery system and still anticipate a profit. Environmental consequences

No appreciable environmental changes seem likely to occur on the Antarctic continent as the result of iceberg towing. Considering that the Antarctic releases $1000 \mathrm{~km}^{3}$ of fresh water each year due to the calving of tabular icebergs, an immense towing effort would be required to make a significant reduction in the number available. Also as icebergs selected for towing have already escaped naturally from the pack-ice zone, it is only the precise location of their demise that would be affected by towing rather than their life-span. The i ceberg would, of course, release a plume of cold water as it is towed, but it is difficult to believe that this would be more than a local effect. The largest side-effects would undoubtedly be felt in the docking and processing area. Local cooling of the surrounding air and sea are a certainty and would probably induce fog and condensation. Considering the furnace-like climate of some of the possible delivery sites, this new environment might actually prove to be a local attraction. The largest effect would be on the marine life in the docking area. However, it must be remembered that even at locations where a bare iceberg could be delivered, the iceberg would have to be immediately encapsulated to entrap the melt water. As such encapsulations would isolate the cold melt water from the surrounding warm seawater, the region affected by the low temperatures would be small. In short, the environmental effects of iceberg water do not appear to be excessive. If other coupled projects are operated in conjunction with an iceberg-water program, they might well have joint environment effects that would be less than if the two projects were operated separately.

\section{Processing}

What does one do when the iceberg arrives? This is a major problem that will need considerable attention if iceberg water is to become a reality. There was only one paper on the subject at Iowa and it examined a very specialized part of the overall problem. Probably the most useful reference at present is Weeks and Me11or (1978) who provide the basic data required by those who wish to know the costs associated with coring, cutting, blasting, or comminuting ice. We know that, even though ice has a low strength and a low density, it is not easy to blast as it is a most effective stress-wave attenuator. For a realistic appraisal of some of the processing difficulties, the reader is referred to the discussion by Bader (1978) who ultimately selected slicing the iceberg into large pieces as the least of the evils. Weeks and Mellor (1978), on the other hand, prefer slurry pipelines. Whatever the answer to the processing problem may be, it will probably be some combination of methods. An additional factor is, of course, the strong possibility of a coupled project which would have a significant effect on optimum processing methods. Certainly, we cannot let a delivered iceberg sit around and melt leisurely in the sun (perhaps hiding beneath its selfinduced fog bank), because it represents a large investment.

It should also be noted that, because of its great draft, the iceberg would not be able to reach a safe harbor at most sites. Instead it would ground far out to sea. For instance, in south-west Australia, the minimum distance off the coast would be $15 \mathrm{~km}$ (off Rottnest Island), and along most of the southern coast of Australia, grounding would occur at approximately $35 \mathrm{~km}$ from the beach (Schwerdtfeger 1979). Stabilizing an iceberg for processing at these near-open ocean sites is far from a trivial ocean-engineering problem, although presumably it is a manageable one. Finally, it should be mentioned that even if the iceberg arrives 
nude at the site, it will immediately have to be surrounded by some sort of a baffle so that the fresh melt water will not mix with the seawater. Recent experimental work by Huppert and Turner (1978) suggests that the oft-quoted scheme suggested by Isaacs of surrounding an iceberg by a shallow curtain which would catch the low-density melt water after it flows up along the iceberg walls will not work because of intense mixing. This is a most interesting subject as it also has oceanographic

consequences. Fortunately, Dr Huppert will discuss these matters during this conference. Clearly, processing and docking are complex problems that require additional attention. Protection

Do you have to protect an iceberg from melting during towing? Probably not on a tow to Australia, if Job's calculations (1978 [a] and $[\mathrm{b}]$, Schwerdtfeger 1979), which are based on the best simulations carried out to date, are near target; he estimates a loss of $50 \%$ during the 2- to 3 -month tow. It should be mentioned here that making realistic combined towing and melting calculations is difficult as the geophysical factors involved in towing are complex, and the complexities of the melting process itself have only recently begun to receive adequate attention. Nevertheless, even on an Australian tow, an efficient, inexpensive protection scheme could be instrumental in saving most of the $50 \%$ of the iceberg that would otherwise be 1 ost.

Protection is essential for tows north of the equator, and particularly for those to sites such as Saudi Arabia. Otherwise the complete iceberg will have melted well before the delivery site is in view. For instance, in July, the tow would have to traverse over $5600 \mathrm{~km}$ with water temperatures higher than $20^{\circ} \mathrm{C}$ (much of the route is actually warmer than $25^{\circ} \mathrm{C}$ (Denner 1978)). Rough calculations presented by Weeks and Mellor (1979) suggest that, even neglecting the appreciable melt losses south of the $20^{\circ} \mathrm{C}$ isotherm, the iceberg will have melted complete$1 y$ on the 104th day of a 128-day voyage.

Can an iceberg be effectively, efficiently, and economically protected? Some people think so; for instance, Hult (1978) favors the use of protective fabrics to retain a cold boundary layer against the ice. Others (Husseiny 1978) have suggested the use of foamed insulation. I chaired a panel at the Iowa meeting that considered this general problem. It was concluded that both plastic films and wraps would be difficult to handle and maintain under the severe environmental conditions that can be expected in the Southern Ocean. The task of protecting the near-vertical 200 to $250 \mathrm{~m}$-high sides of an iceberg under tow is formidable as the physical hazard of operating near these ice cliffs is extreme. It should be remembered also that both the sides and the bottom of the iceberg require protection.

In the light of recent advances in engineering, it would probably be foolish to state that protection could not be achieved. However, I do not know how to do it and I do not know anyone else who, having had experience with real icebergs, believes that he has an answer. If iceberg towing has an Achilles' heel, this may well be it, in that, if protection is not possible, then tows to northern hemisphere sites are also impossible.
Propulsion

Can large icebergs be towed? In principle the answer is yes. Performing an adequate simulation of this process is not easy, as a perusal of the papers by Weeks and Campbell (1973), Hult and Ostrander (1973), and Chirivella and Miller (1978) should convince you. As I mentioned earlier, the best attempt to date appears to be the work of Job (1978 [a] and [b]) who took a large number of factors into consideration. Such simulations should be up-dated continuously as our knowledge of the different factors involved improves.

There appear to be two main problems in towing. Firstly, all simulations agree that the power requirements for such tows are 1 arge and are beyond the capability of the largest existing tugs. A number of exotic methods have been suggested to help in the generation of the large bollard pulls required (feathered paddle wheels, drogue parachutes, osmotic propulsion, kedging, even self-propulsion (Husseiny 1978)). Generally, however, it is felt that relatively standard procedures (i.e. tugs) would probably be used to initiate a towing operation. Mellor (1980) has reviewed this overall problem, pointing out that as tug size increases, the thrust/power ratio invariably decreases, giving a supertug less than half the efficiency of small tugs. The simplest solution to this problem would be to use multiple small tugs to start a tow, decreasing their number as the tow proceeds. This procedure would also help resolve another problem: that the safe working load of the largest available wire rope is $3 \frac{1}{2}$ times less than the force required to move a usefulsized Antarctic iceberg.

Secondly, the other main propulsion problem is the operational difficulty of carrying out such a tow. The Southern Ocean is a formidable location, even when one is not tied to an iceberg. We (Weeks and Mellor 1979) have talked to a number of people and obtained varied opinions of the operational difficulties. On the whole, it was felt that towing operations were possible although they would not be easy, and that the best way to appraise problems realistically would be to experiment with test tows on a modest scale using several techniques. I ceberg properties

In his keynote address to the Iowa meeting, Henri Bader (1978) pointed out, with his usual insight and rapier-1ike wit, that the authors of the early papers on iceberg water had largely neglected the physical properties of real icebergs. I, for one, plead guilty. However, in my defense, let me point out that many of the important iceberg characteristics that should be known are not known. This can be seen in the paper of Weeks and Mellor (1978), in which we tried to make amends to Henri by collecting as much glaciological data as we could find that was pertinent to iceberg water and assembling it in one paper convenient to the non-specialist (another highly useful recent reference is Robe (1980)). Note that we invariably used ice properties collected at iceshelf sites (many times from sites located some distance from the ice front) to describe calved icebergs, as nothing was known about the internal state of real tabular Antarctic iceberirs, particularly those that had drifted to locations in the vicinity of the Antarctic convergence. Fortunately, we will have some 
observations on real Antarctic icebergs reported to us in a few minutes.

There are several reasons why we should be interested in the properties of icebergs.

Firstly, the upper portions of tabular icebergs are composed of snow (permeable to fluids), with the snow-ice transition occurring at a depth of 40 to $60 \mathrm{~m}$, depending on the exact site of origin of the iceberg. This snow layer must be considered by those who propose to form unlined lakes on the upper surface (very leaky) or fix towing bollards in the snow (very weak unless properly installed). Also, if the snowice transition occurs below the water line, sea-water will be able to percolate into the upper part of the iceberg, raising its salinity and presumably decreasing its strength. Secondly, many icebergs contain flaws such as cracks and crevasses that sea-water exploits to speed their break-up (Robe and others 1977). Whether such flaws are intrinsic to all Antarctic icebergs, or whether icebergs can be selected that are structurally sound, is unknown. Thirdly, questions have been posed (Weeks and Mellor 1978) concerning the stability of icebergs of greater than a certain critical size when exposed to long-period swell. It is not encouraging to note that intense storms in the Southern Ocean are the sources of much of this type of swell. We will soon hear of field observations relating to this general problem. One thing is certain: some large icebergs survive for years in the open ocean and sail far to the north on their own. In the African, Australian, Pacific, and South American sectors of the world's oceans, icebergs have been sighted at latitudes of $34^{\circ}, 42^{\circ}, 40^{\circ}$, and $30^{\circ} \mathrm{S}$., respectively (Burrows 1976). Dó these survivors have some special character istic? No one knows.

I would guess that iceberg integrity may well be iceberg water's second Achilles' heel. It will be difficult enough to tow an iceberg that stays intact. If an iceberg splits and splits and splits, the tow-er will have a tough time keeping things glued together. Also, each additional fracture gives water a place to work at, further weakening the ice mass.

Iceberg selection

It is always nice to end on a high note and, as remote sensing of snow and ice masses has developed rapidly in the last few years, I am able to do so. By the time that an iceberg-water scheme could become operational, it seems likely that NASA will have launched an operational synthetic aperture radar (SAR) system into a polar orbit. Although the exact specifications of such a system are unknown, its resolution would almost certainly be $50 \mathrm{~m}$ or less (adequate for i ceberg tracking). The operation of such a system would allow the locations of icebergs to be determined every few days during all weather and light conditions. The SAR data could also be supplemented with visual or near-infrared observations via Landsat when clouds and light permit.

Presumably, once the field of potential tow-ees has narrowed by natural selection to a few candidates, an on-site inspection would be made using one or more varieties of a radio echosounding system. It is known that such systems can locate the presence of crevasses and other flaws. Whether or not it can locate critical flaws (if there are any) remains to be determined. In summary, when it comes to iceberg reconnaissance and selection we appear to be in good shape.

Another important aspect of remote sensing will be in selecting the best route for towing. Because of the very slow response time of a towed iceberg, strategies for crossing storm systems would have to be implemented days in advance of the actual arrival of the storm. Another important potential problem, which can be handled through the application of space technology, and possibly even turned to a tow-er's advantage, is the formation and migration of large $(\sim 200 \mathrm{~km})$ rings and eddies in association with prevailing current systems (Campbell and others 1980). As current velocities as great as $1.5 \mathrm{~m} / \mathrm{s}$ have been observed in the rings, and velocities of $0.5 \mathrm{~m} / \mathrm{s}$ are common, these phenomena cannot be ignored.

\section{CONCLUSION}

If my analysis of the difficulties that must be confronted and resolved is correct, iceberg-water advocates certainly have enough problems to keep themselves occupied for some time to come. Is iceberg water a real possibility or just a pipe dream? If it can be ascertained that large icebergs will stay intact during a tow of several months, then iceberg water may indeed prove to be an interesting alternative water source for southern hemisphere sites such as Australia. How attractive this alternative is will depend upon the overall economics of the complete scheme, a value that has not yet been determined. Before sites north of the equator such as southern California and Saudi Arabia can be considered as possibilities the protection problem must be solved. This is, in my opinion, a tall order.

Normally, in a paper such as the present one I would conclude by regaling you with a long list of important research projects that must be carried out (part of my plan to keep glaciologists fully employed). However, I note with some relief that this subject will be addressed by one and all during the closing session. It would be unseemly of me to beat you to the punch by listing all your favorite unresolved problems; therefore I will not do so! Besides, we will not know what is unresolved until we listen to the technical papers that will start as soon as I stop.

\section{ACKNOWLEUGEMENTS}

I would like to thank my colleague M. Mellor for his helpful discussions. The discerning reader will recognize that I have, in the present paper, used an appreciable amount of material from a recent paper that we coauthored (Weeks and Mellor 1979).

\section{REFERENCES}

Al Faisal, Prince Mohammed In press. New water resources for desert development from icebergs. In Schechter J (ed.) Alternative strategies for desert development and management. Papers submitted to the UNITAR-State of California conference, 1977. New York, Pergamon Press

Bader H 1978 A critical look at the iceberg utilization project. In Husseiny A A (ed.) Iceberg utilization. Proceedings 
of the first International Conference, Ames, Iowa, 1977. New York, Pergamon Press: $34-44$

Bishop W W Jr 1978 International law problems of acquisition and transportation of Antarctic icebergs. In Husseiny A A (ed.) Iceberg utilization. Proceedings of the first Intermational Conference, Ames, Iowa, 1977. New York, Pergamon Press: $586-596$

Burrows C J 1976 Icebergs in the Southern Ocean. New ZeaZand Geographer 32 (1): $127-138$

Burt J C 1956[a] The battle of the bergs. Natural History 65(4): 186-191

Burt J C 1956[b] Iceberg water for California? Science Digest $39(2)$ : 1-4

Burton S J 1978 Lega1/political aspects of Antarctic iceberg utilization. In Husseiny A A (ed.) Iceberg utilization Proceedings of the first Intemationat Conference, Ames, Iowa, 1977. New York, Pergamon Press: 604-615

Campbel1 W J, Cheney R E, Marsh J G, Mognard N M 1980 Ocean eddy structure by satellite radar altimetry required for iceberg towing. Cold Regions Science and Technology 1(3-4): 211-221

Chamoux J-P 1978 Some international implications of iceberg transfer In Husseiny A A (ed.) Iceberg utilization. Proceedings of the first International Conference, Ames, Iowa, 1977. New York, Pergamon Press: 597-603

Chirivella J E, Miller C G 1978 Hydrodynamics of icebergs in transit. In Husseiny A A (ed.) Iceberg utilization. Proceedings of the first International Conference, Ames, Iowa, 1977. New York, Pergamon Press: 315-333

Denner W W 1978 Environmental factors along an iceberg tow route in the Indian Ocean. In Husseiny A A (ed.) Iceberg utilization. Proceedings of the first Intermational Conference, Ames, Iowa, 1977. New York, Pergamon Press: 389-416

Heizer R T 1978 Energy and fresh water production from icebergs. In Husseiny A A (ed.) Iceberg utilization. Proceedings of the first Intemational Conference, Ames, Iowa, 1977. New York, Pergamon Press: 657-673

Hult J L 1978 A pilot program for exporting Antarctic icebergs. In Husseiny A A (ed.) Iceberg utilization. Proceedings of the first Intermational Conference, Ames, Iowa, 1977. New York, Pergamon Press: 528-535

Hult J L, Ostrander N C 1973 Antaretic icebergs as a global fresh water resource. Santa Monica,California, Rand Corporation (R1255-NSF)

Huppert H E, Turner J S 1978 On melting icebergs. Nature 271(5640): 46-48

Husseiny A A (ed.) 1978 Iceberg utilization. Proceedings of the first International Conference, Ames, Iowa, 1977. New York, Pergamon Press

Job J G 1978[a] Numerical modelling of iceberg towing for water supplies - a case study. Joumal of Glaciology 20(84): 533-542
Job J G 1978[b] Yields and energetics in moving unprotected icebergs to southern continents. In Husseiny A A (ed.) Iceberg utilization. Proceedings of the first International Conference, Ames, Iowa, 1977. New York, Pergamon Press: 503-527

Mellor M 1980 High-force towing. Cold Regions Science and Technology 1(3-4): 231-240

Robe R Q 1980 Iceberg drift and deterioration. In Colbeck S C (ed.) Dynamics of snow and ice masses. New York, Academic Press: 211-259

Robe R Q, Maier D C, Kollmeyer R C 1977 Iceberg deterioration. Nature 267(5611): 505-506

Roberts D M 1978 Icebergs as a heat sink for power generation. In Husseiny A A $(e d$. Iceberg utilization. Proceedings of the first Intemational Conference, Ames, Iowa, 1977. New York, Pergamon Press: 674-688

Russel1 WE (ed.) 1980 Iceberg dynamics symposium, June 4 and 5, 1979, St. John's, Newfoundland, Canada. Cold Regions Science and Technology 1(3-4): $167-310$

Schwerdtfeger P 1979 On icebergs and their uses. Cold Regions Science and Technology 1(1): 59-79

Weeks W F, Campbe11 W J 1973 Icebergs as a fresh water source: an appraisal. Joumal of Glaciology 12(65): 207-232

Weeks W F, Mellor M 1978 Some elements of iceberg technology In Husseiny A A (ed.) Iceberg utilization. Proceedings of the first Intemationat Conference, Ames, Iowa, 1977. New York, Pergamon Press: 45-98

Weeks WF, Mellor M 1979 The iceberg cometh. Technology Review 81(8): 66-75 